Volume 39

Issue 4 December

Article 8

2012

\title{
Perceived Neighborhood Safety and Psychological Distress: Exploring Protective Factors
}

Jaime Booth

Arizona State University

Stephanie L. Ayers

Arizona State University

Flavio F. Marsiglia

Arizona State University

Follow this and additional works at: https://scholarworks.wmich.edu/jssw

Part of the Clinical and Medical Social Work Commons, Human Ecology Commons, and the Social Work Commons

\section{Recommended Citation}

Booth, Jaime; Ayers, Stephanie L.; and Marsiglia, Flavio F. (2012) "Perceived Neighborhood Safety and Psychological Distress: Exploring Protective Factors," The Journal of Sociology \& Social Welfare: Vol. 39 : Iss. 4 , Article 8.

Available at: https://scholarworks.wmich.edu/jssw/vol39/iss4/8 


\title{
Perceived Neighborhood Safety and Psychological Distress: Exploring Protective Factors
}

\author{
JAIME BOOTH \\ StePHANIE L. AyERS \\ Flavio F. Marsiglia
}

\section{Arizona State University School of Social Work}

While a growing body of literature has established a relationship between "disordered" neighborhoods and psychological distress, less is known about the specific mechanisms at work. Using data collected in the 2008 Arizona Health Survey $(N=4,196)$, hierarchal linear regression was conducted to assess both the independent effect of perception of neighborhood safety on psychological distress, as well as the mediating effects of powerlessness, social isolation and mistrust. The findings suggest that the more safe individuals feel in their neighborhood, the less psychological distress they experience $(b=1.07, S E=.17, p<.001)$. This relationship appears to be partially mediated by feelings of powerlessness, social isolation and mistrust, indicating potential risk and protective factors.

Key words: Psychological distress, neighborhood safety, ecological systems theory, Arizona adults

Mental health disorders are a leading source of disability, making it an important aspect of public health. Rates of depression and anxiety are between 10 and $20 \%$ in populations worldwide (Patel, Flisher \& Cohen, 2006) with psychological disorders accounting for $12 \%$ of all disability-adjusted life years lost (Brundtland, 2000). Poor mental health has a variety

Journal of Sociology \& Social Welfare, December 2012, Volume XXXIX, Number 4 
of social consequences including, but not limited to, marital instability (Kessler, Walters \& Forthofer, 1998), increased teenage parenthood (Kessler et al., 1997), substance abuse (Regier et al., 1990), disruptions in social relationships (Mickelson \& Kessler, 1997), and suicide (Prince et al., 2007).

In a classic study, Faris and Dunham (1939) established a relationship between some mental health outcomes and geographical location, suggesting that the environment in which a person lives may impact the development of mental health symptoms. They attributed this relationship to the lack of social infrastructure in disordered neighborhoods, which adds to the existing impact of individual-level characteristics. Although Faris and Dunham (1939) found that this relationship only held true for individuals hospitalized for psychotic and substance abuse disorders and were not able to control for individual factors, subsequent research has established a link between neighborhood environments and anxiety/depression, controlling for individual-level characteristics (Beard et al., 2009; Galea et al., 2007; Roh et al., 2011; Silver, Mulvey, \& Swanson, 2002; Truong \& Ma, 2006).

In a review of the literature examining the independent relationship between neighborhood characteristics and depression, thirty-seven of the forty-five studies found support for the hypothesis (Mair, Roux, \& Galea, 2008). While these studies have looked at the association between disordered neighborhood and mental health, few have explored the specific relationship between perception of neighborhood safety and psychological distress. In addition, no studies, to our knowledge, have explored the secondary stressors, such as powerlessness, social isolation and mistrust, that may link the external stressor of neighborhood safety to the internalization of psychological distress.

Based on an ecological systems theory and the social stress theory perspectives, the present study approaches perception of neighborhood as one important aspect in the complex constellation of factors contributing to psychological distress. In order to do this, we examine the associations between a primary stressor, perception of neighborhood safety, and psychological distress and explore to what degree this relationship is mediated by secondary stressors, such as 
powerlessness, mistrust and social isolation for adults living in Arizona.

Ecological systems theory conceives of the "environment" as nested structures with multiple layers surrounding and impacting the individual (micro, exo, and macro) (Bronfenbrenner, 1977). Within this system, an individual naturally strives to maintain a balance between resources and demands. According to this theory, psychological distress, which includes mental health outcomes such as anxiety and depression, arises when a person is unable to re-achieve equilibrium or adapts in a way that temporarily relieves stress but leads to additional stressors (i.e., substance abuse, illegal activity) (Saleebey, 2004).

The transition from simply experiencing external stress to internalizing and experiencing psychological distress can also be understood in the context of social stress theory. Like ecological systems theory, social stress theory classically defines stress as a state of arousal resulting either from the presence of socio-environmental demands that challenge the ordinary adaptive abilities of the individual or from the absence of means to obtain something wanted or needed (Aneshensel, 1992; Pearlin, 1989). Stress is, therefore, an internal response to an external situation or stressor (Aneshensel, 1992).

In the social stress literature, a distinction has been made between two types of stressors: acute and chronic. While acute stressors rarely result in negative health outcomes or long term psychological distress (Aneshensel, 1992; Thoits, 1983), a large body of evidence has accumulated which links chronic stressors to psychological distress (Avison \& Turner 1988; Downey \& Van Willigen, 2005; House, Strecher, Metzner, \& Robbins, 1986; Ross \& Huber, 1985; Williams, Neighbors, \& Jackson, 2008).

In addition to the distinction between chronic and acute stressors, there is also a distinction between primary and secondary stressors. Stressors are rarely isolated events, with every initial chronic stressor potentially having several secondary stressors that arise as a person reacts to the initial stressor (Elliott, 2000). For example, the loss of employment can be considered a primary stressor and potential secondary stressors may include marital instability, financial insecurity, a lost sense of purpose, or diminished confidence. According 
to social stress theory, different experiences of secondary stressors may explain why two people who experience the same primary stressor have different levels of overall distress (Fitzpatrick \& LaGory, 2003). In this study, the manifestation of distress for those living in an unsafe environment may depend on an individual's experience of secondary stressors-powerless, mistrust and social isolation-and the absence of these secondary stressors may serve as protective factors.

Although individuals may not be aware of the influence of neighborhood on their overall well-being, when disorganized, the place in which a person lives can be a chronic stressor. Increasingly, researchers have been investigating the direct relationship between neighborhood characteristics and psychological well-being, strengthening the evidence that neighborhood factors have an impact on mental health outcomes above and beyond individual characteristics (Beard et al., 2009; Elliot, 2000; Phongsavan, Chey, Bauman, Brooks, \& Silove, 2006; Propper et al., 2005; Wen, Hawkly, \& Cacioppo, 2006). Both physical (Ellaway, Macintyre, \& Kearns, 2001; Ross \& Mirowsky, 2009) and social aspects (Aneshensel \& Sucoff, 1996; Phongsavan et al., 2006; Propper et al., 2005; Wen, Hawkly, \& Cacioppo, 2006) of neighborhood disorganization have been associated with an increased likelihood of poor mental health outcomes, including elevated depressive symptoms and anxiety.

More specifically, Galea et al. (2005) found that New York city residents living in neighborhoods characterized by a poorer internal environments (cracks in the wall, poor ventilation, presence of pests) and external environments (empty lots, abandoned buildings, broken windows, trash) were 29 to $58 \%$ more likely to report depression in the last 6 months and 36 to $64 \%$ more likely to report lifetime depression than persons living in neighborhoods characterized by a less disorganized physical environment. In the first study to use an experimental design to assess neighborhood effects, it was found that parents who moved to mixed income neighborhoods from high poverty neighborhoods experienced an $8 \%$ to $33 \%$ decline in psychological distress and depressive symptoms, while boys age 8-13 years of age experienced a $25 \%$ decrease in depressive/anxiety and dependency problems (Leventhal 
\& Brooks-Gunn, 2003). Additionally, in Los Angeles, a relationship was found between adolescents who described their neighborhoods as having ambient hazards and their reported depressive symptoms (Aneshensel \& Sucoff, 1996).

In addition to the direct effect via chronic stressors, perceptions of neighborhood disorganization may also have indirect effects on psychological distress by impacting the residents' coping resources, such as social cohesion (Aneshensel \& Sucoff, 1996; Ellaway, Macintyre, \& Kearns, 2001; Faris \& Dunham, 1939), trust, and power (Ahern \& Galea, 2011; Ross \& Mirowsky, 2009), leading to feelings of social isolation, mistrust, and powerlessness (Phongsavan et al., 2006; Ross \& Jang, 2000; Stockdale et al., 2007). It has been suggested that mistrust, defined as a lack of faith and confidence in others, is a natural protective reaction to neighborhood disorder (Ross, Mirowsky, \& Pribesh, 2001). This protective reaction is the secondary stressor that may occur as a result of the chronic stress of living in a threatening environment. It follows, then, that in a neighborhood where a person views neighbors as a potential threat, interactions with neighbors and supportive relationships are less likely to be formed (Liska, 1997; Stockdale et al., 2007). Lack of informal social networks and feeling socially isolated in a disordered neighborhood can also increase individuals' feelings of fear and mistrust (Ross \& Jang, 2000). Because social support has been shown to buffer the effect of stressors, minimal social support may make a person susceptible to psychological distress (Brown et al., 2009; Kessler \& McLeod, 1985; Stockdale et al., 2007).

In addition, an unsafe or disordered neighborhood may also lead to feelings of powerlessness-defined as the feeling that the outcomes of one's life are determined by forces outside of oneself-because neighborhood stressors create a sense that life is chaotic and full of uncontrollable threats (Geis \& Ross, 1998). Bandura (2000) writes that perception of self efficacy, the conceptual opposite of feelings of powerlessness, impact an individual's ability to cope with stressful environments. A threatening neighborhood environment may also lead to feelings of powerlessness when a person is not able to move out of the area, communicating to individuals that they are not able to meet their basic need for safety (Hiroto, 1974). It follows that 
perceptions of mastery or self efficacy have been found to be inversely associated with psychological distress (Aneshensel, 1992). While Sampson et al. (1997) have argued that collective efficacy, which is dependent on social cohesion and trust, is related to decreased levels of violence in a neighborhood, Ross \& Mirowsky (2009) posit that disorder, including feelings of safety, impact individual feelings of efficacy, trust and social cohesion. They go on to state that it is these secondary stressors, powerlessness, mistrust and social isolation, that connect living in a disordered neighborhood and psychological distress (Ross \& Mirowsky, 2009).

While these direct and indirect relationships have been explored, tested, and supported for "neighborhood disorder," previous research has tended to aggregate many neighborhood stressors, including graffiti, vacant lots, crime, loitering, and drug use, in order to characterize it as hazardous or "disordered" (Aneshensel \& Sucoff, 1996; Ellaway et al., 2001; Ross \& Mirowsky, 2009; Sampson \& Raudenbush, 2004). Although aggregating stressors is helpful in determining which neighborhoods may be considered high risk, this approach makes it difficult to determine exactly what about living in a "disordered" environment impacts psychological distress.

It has been suggested that after the most basic needs of food and shelter have been met, an individual's attention naturally shifts to safety or securing one's environment (Maslow, 1987). In a discussion about a neighborhood's influence on all aspects of health, Taylor, Repetti and Seeman (1997, p. 439) define healthy environments as those "that provide safety and opportunities for social integration." In one of the few studies that have examined perceptions of safety and mental health outcomes independently, Roh and colleagues (2011) found that perceptions of neighborhood safety significantly predicted depressive symptoms among older Korean adults. Based on theory and the limited evidence available, perceptions of neighborhood safety may have a significant effect on psychological distress and should be examined independent of other neighborhood indicators.

The overall hypothesis guiding the study is that feeling unsafe in one's neighborhood will act as a primary stressor on psychological distress. Thus, the more unsafe a person feels in 
his or her neighborhood, the higher the psychological distress, indicating a positive relationship. However, when feelings of trust, power, and neighborhood social support are present, the primary stressor of living in an unsafe neighborhood may not lead to psychological distress, thereby mediating the relationship and providing potential protective factors to living in disordered neighborhoods, the secondary hypothesis.

\section{Methods}

\section{Sample}

Data used in this study came from the Arizona Health Survey (AHS) collected in the early part of 2008 and sponsored by the St. Luke's Health Initiatives. The AHS, a populationbased, random-digit dialing telephone survey, is intended to be representative of Arizona's non-institutionalized population living in households with a landline-based phone. A multi-stage sampling design was used and residential telephone numbers were selected within two geographic strataMaricopa County and the remainder of Arizona. The final sample size included 3,130 adults living in Maricopa County and 1,066 living in the remainder of Arizona, totaling 4,196 adults. Within each household, one adult was randomly selected to complete the survey. Interviews were conducted in English and Spanish using a computer-assisted telephone interviewing system. To maximize the response rate, letters were mailed to households selected for which addresses could be obtained prior to the telephone survey.

The overall response rate was a composite of the screener completion rate (i.e., success in introducing the survey to a household and randomly selecting an adult to be interviewed) and the extended interview completion rate (the success of getting one or more selected persons to complete the extended interview). The screener completion rate was $36.6 \%$ and the extended interview completion rate was $53.7 \%$, resulting in a $19.2 \%$ overall response rate (Arizona Health Survey, 2008). Because AHS was not successful in obtaining a demographically representative sample of Arizonans, the data were weighted so that they could be generalized to the entire population of Arizona. 


\section{Measures}

Psychological distress was measured using the Kessler 6 (Kessler et al., 2002) which has been shown to be highly correlated with a clinical mental health diagnosis (Wells, Bushness, Hornblow, Joyce, \& Oakley-Browne, 1989) and sociocultural variations in rates of diagnosis (Wakefield, 1999). Respondents were asked about the severity of certain signs of stress, and responses were then combined to give a score that represents a person's overall level of psychological distress. The Kessler 6 score is an aggregate of the participant's response to six questions $(\alpha=.80)$ : (a) "About how often in the past 30 days did you feel nervous?" (b) "During the past 30 days, about how often did you feel helpless?" (c) "During the past 30 days, about how often did you feel restless or fidgety?" (d) "During the past 30 days, how often did you feel so depressed that nothing could cheer you up?" (e) "During the past 30 days, about how often did you feel that everything was an effort?" and (f) "During the past 30 days, about how often did you feel worthless?" Responses to each question were coded as 0 , "None of the time," thru 4 "All of the time." The final aggregate measure ranged from 0 - 24, with higher scores indicating greater levels of psychological distress.

Perception of Feeling Unsafe in the Neighborhood is a subjective measure of neighborhood safety. Perception of feeling unsafe in the neighborhood was measured using the question: "Do you feel safe in your neighborhood?" with responses ranging from (1) "All of the time" to (4) "None of the time." While using objective measures of safety (i.e., amount of criminal activity in the neighborhood) is a more traditional way of conceptualizing a variety of aspects of neighborhood disorder (Macintyre \& Ellaway, 2003; Ross \& Mirowsky, 2009), subjective experiences and perceptions are a more directly related to health (ChristieMizell, Steelman, \& Stewart, 2003) and are high correlated with objective measures (Austin, Furr, \& Spine, 2002; Ellaway, Macintyre, \& Kearns, 2001; Sampson \& Raudenbush, 2004) .

Powerlessness was measured with the following question, "Please tell me how often the statements were true of you over the past month...You felt in control of your life." The responses ranged from (1) "All of the time" to (5) "None of the time." In order to measure a person's level of neighborhood mistrust, 
the participants were asked, "Tell me if you strongly agree, agree, disagree or strongly disagree with the following statement...People in my neighborhood can be trusted." The responses were given values ranging from (1) "Strongly agree" to (4) "Strongly disagree." In order to measure levels of perceived social isolation the following questions were considered: "Tell me if you strongly agree, agree, disagree or strongly disagree with the following statement... (a) "People in my neighborhood help each other out" and (b) "There are people I can count on in this neighborhood" $(\alpha=.74)$. The responses were given values ranging from (1) "Strongly agree" to (4) "Strongly disagree." The average value of these two questions was calculated and a mean scaled variable was constructed.

\section{Statistical Analysis}

Using Stata 10.0, hierarchal linear regressions were conducted to assess both the independent effects of perception of safety, powerlessness, social isolation and mistrust on psychological distress, as well as the mediating effects controlling for marital status, age, gender, race education and income. To test for mediation, the four-step process proposed by Barron and Kenny (1986) was used: Step 1) The relationship between perceived neighborhood safety and psychological distress was tested; Step 2) The relationship between perceived neighborhood safety and a mediator variable (powerlessness, social isolation, or mistrust) was tested; Step 3) The relationship between the mediator and psychological distress was tested; and Step 4) Both perceived neighborhood safety and a mediating variable were entered into the multiple regression equation. If the relationship between perceived neighborhood safety and psychological distress decreases when the mediator is added to the model, then mediation is present. A Sobel (1982) test was used to determine if the decrease in psychological distress observed was statistically significant. For all models, weights were applied and standard errors were adjusted by stratum, Maricopa County and all other counties, to adjust for any bias in the sampling procedure. 


\section{Results}

After the data were weighted, $49 \%$ of respondents reported that they were female and $65 \%$ were married. The majority of respondents were non-Hispanic white $(71 \%)$, followed by Hispanic (26\%) and African American (3\%). On average, participants completed some college $(\mathrm{M}=14.69, \mathrm{SD}=4.99)$, were 47 years old $(M=46.96, S D=18.64)$ and reported earnings between $\$ 50,000$ and $\$ 60,000$ a year $(M=7.94, S D=4.19)$.

Table 1. Steps 1, 2 and 3. The Relationship between Perception of Neighborhood Safety and Psychological Distress with Powerlessness, Community Isolation, and Mistrust as Mediators

\begin{tabular}{lcccc}
\hline & $\begin{array}{c}\text { Psychological } \\
\text { Distress }\end{array}$ & Powerlessness & Social Isolation & Mistrust \\
\hline $\begin{array}{l}\text { Step 1 } \\
\text { Feeling unsafe in } \\
\text { neighborhood }\end{array}$ & $1.07(.17)^{* * *}$ & & & \\
$\begin{array}{l}\text { Step 2 } \\
\text { Feeling unsafe in } \\
\text { neighborhood }\end{array}$ & & & & \\
$\begin{array}{l}\text { Step 3 } \\
\text { Powerlessness }\end{array}$ & $1.92(.12)^{* * *}$ & & & \\
Social Isolation & $.95(.18)^{* * *}$ & & & \\
Mistrust & $.65(.16)^{* * *}$ & & & \\
\hline
\end{tabular}

Note: all independent variables were modeled separately; all models control for marital status, age, gender, race, education and income. ${ }^{*} \mathrm{p}<.05,{ }^{* *} \mathrm{p}<.01,{ }^{* * *} \mathrm{p}<.001$

The mean Kessler 6 score was $3.85(\mathrm{SD}=3.78)$, indicating that on average people reported experiencing low levels of psychological distress. When asked if they felt safe in their neighborhood, $63 \%$ reported that they did all of the time, $30 \%$ reported they did most of the time, $6 \%$ reported that they did some of the time and $1 \%$ reported that they did none of the time. When asked if they felt in control of their lives, $37 \%$ of participants reported that they did all of the time, $42 \%$ reported that they did most of the time, $14 \%$ some of the time, $4 \%$ a little of the time and $3 \%$ none of the time. When asked if they agreed that "people in their neighborhood could be trusted," $23 \%$ stated that they strongly agree, $63 \%$ reported that they agree, $10 \%$ reported that they disagree and $2 \%$ reported that they strongly disagree. The mean of the neighborhood social isolation scale 
was $1.88(\mathrm{SD}=.59)$, indicating that on average people "agree" that people in their neighborhood help each other out and can be counted on.

Step 1) A statistically significant positive relationship was found between perceptions of feeling unsafe in the neighborhood and psychological distress when controlling for marital status, age, gender, race, education and income $\left(b_{1}=1.07, S E\right.$ $=.17, p<.001$ ) (see Table 1 ). As perceptions that a neighborhood is unsafe increases, psychological distress increases. This model accounted for $11.69 \%$ of the variation in psychological distress.

Step 2) Like Step 1, all models control for marital status, age, gender, race, education and income. A statistically significant positive relationship was found between perception of feeling unsafe in the neighborhood and feelings of powerlessness $\left(b_{1}=.22, S E=.04, p<.001\right)$, between feeling unsafe in the neighborhood and feelings of social isolation $\left(b_{1}=.20, S E=.02\right.$, $p<.001$ ), and between feeling unsafe in the neighborhood and feelings of mistrust $\left(b_{1}=.28, S E=.03, p<.001\right)$ (See Table 1 ).

Table 2. Step 4. OLS Regression of Perception of Neighborhood Safety and Psychological Distress introducing Mediating Variables

\begin{tabular}{lccc}
\hline & $\begin{array}{c}\text { Model 1 } \\
\mathrm{b}(\mathrm{SE})\end{array}$ & $\begin{array}{c}\text { Model 2 } \\
\mathrm{b}(\mathrm{SE})\end{array}$ & $\begin{array}{c}\text { Model 3 } \\
\mathrm{b}(\mathrm{SE})\end{array}$ \\
\hline Married & $-.38(.17)^{*}$ & $-.58(.23)^{* *}$ & $-.46(.23)^{*}$ \\
Age & $-.02(.00)^{* * *}$ & $-.03(.01)^{* * *}$ & $-.03(.01)^{* * *}$ \\
Gender (Male) & $.11(.16)$ & $.33(.19)$ & $.30(.20)$ \\
Race (Hispanic) & $.23(.22)$ & $-.38(.27)$ & $-.37(.27)$ \\
Race (African American) & $.03(.37)$ & $-.07(.39)$ & $-.32(.36)$ \\
Education & $-.07(.02)^{* * *}$ & $-.07(.02)^{* * *}$ & $-.06(.02)^{* * *}$ \\
Income & $-.11(.02)^{* * *}$ & $-.12(.02)^{* * *}$ & $-.12(.02)^{* * *}$ \\
Feeling unsafe in neighborhood & $.65(.15)^{* * *}$ & $.96(.18)^{* * *}$ & $.96(.18)^{* * *}$ \\
Powerlessness & $1.85(.13)^{* * *}$ & & \\
Social Isolation & & $.73(.18)^{* * *}$ & \\
Mistrust & & & $.37(.16)^{*}$ \\
Model R-Square & & $13.04 \%$ & $12.17 \%$ \\
F-test & $32.09 \%$ & $19.70^{* * *}$ & $5.35^{*}$ \\
Change in R-Square & $189.09^{* * *}$ & $1.13 \%$ & $0.36 \%$ \\
\hline
\end{tabular}

Note: Dependent (outcome) variable - psychological distress (Kessler) ${ }^{*} \mathrm{p}<.05,{ }^{* *} \mathrm{p}<.01,{ }^{* * *} \mathrm{p}<.001$ 
Step 3) As Table 1 shows and controlling for marital status, age, gender, race, education and income, a statistically significant positive relationship was found between powerlessness and psychological distress $\left(b_{1}=1.92, S E=.12, p<.001\right)$, between social isolation and psychological distress $\left(b_{1}=.95, S E\right.$ $=.18, p<.001)$, and between mistrust and psychological distress $\left(b_{1}=.65, S E=.16, p<.001\right)$.

Step 4) Table 2 presents the tests of mediation. A statistically significant positive relationship remained between perception of feeling unsafe in the neighborhood and psychological distress when testing for mediation of powerlessness $\left(b_{1}=\right.$ $.65, S E=.15, p<.001)$. However, it decreased from the original model $\left(b_{1}=1.07, S E=.17, p<.001\right)$, indicating that feelings of powerlessness partially mediate the relationship between perception of feeling unsafe in the neighborhood and psychological distress.

With the addition of powerlessness, this model accounted for $32.09 \%$ of the variation in psychological distress. When conducting a Sobel test, the indirect effect was found to be statistically significant (Sobel test statistic $=5.20, p<.01$ ) (not shown). A statistically significant positive relationship also remained between perception of feeling unsafe in the neighborhood and psychological distress when testing for mediation of neighborhood social isolation $\left(b_{1}=.73, S E=.18, p<.001\right)$, but again it decreased from the original model $\left(b_{1}=1.07, S E=.17, p<\right.$ .001 ). Feelings of social isolation partially mediate the relationship between perception of feeling unsafe in the neighborhood and psychological distress. With the addition of neighborhood social isolation, this model accounted for $13.04 \%$ of the variation in psychological distress.

The Sobel test indicated a statistically significant indirect effect (Sobel test statistic $=4.67, p<.01$ ) (not shown). A statistically significant positive relationship remained between perception of feeling unsafe in the neighborhood and psychological distress when testing for mediation of mistrust $\left(b_{1}=.96\right.$, $S E=.18, p<.001)$, and, like powerlessness and neighborhood social isolation, decreased from the original model $\left(b_{1}=1.07\right.$, $S E=.17, p<.001)$ and indicates that feelings of social isolation partially mediates the relationship between perceptions of feeling unsafe in the neighborhood and psychological distress. 
With the addition of mistrust, this model accounted for $12.17 \%$ of the variation in psychological distress. The Sobel test indicated the indirect effect was statistically significant (Sobel test statistic $=3.72, p<.01)($ not shown $)$.

\section{Discussion}

Adding to the growing body of literature examining the relationships between neighborhood factors and mental health, the purpose of this study was to examine the specific association between perceptions of neighborhood safety and psychological distress. The hypothesis that a person's perception of neighborhood safety is positively associated with psychological distress was confirmed, indicating the more unsafe a person feels in their neighborhood, the more psychological distress he or she reports. This finding is consistent with previous studies that found that neighborhood factors are associated with mental health outcomes (Eliot, 2000; Leventhal \& Brooks-Gunn, 2003; Phongsavan et al., 2006; Propper et al, 2005; Wen et al., 2006), however this study provides new information about the importance of perception of neighborhood safety when discussing the impact of neighborhood disorganization on individual mental health outcomes. The relationship found between perception of neighborhood safety and psychological distress supports social stress theory in its assertion that chronic stressors which occur outside of the individual are related to internalized feelings of distress (Ahern \& Galea, 2011; Fitzpatrick \& LaGory, 2003). While the implied direction of the relationship is based on ecological systems theory and supported by previous research (Leventhal \& Brooks-Gunn, 2003), causal conclusions cannot be made due to the cross-sectional nature of the data. Despite the inability to make concrete causal claims, this study establishes a relationship between perception of safety and psychological distress and suggests that more research is needed to investigate how this aspect of the neighborhood environment impacts mental health.

In addition, this study aimed to test the mediating effects of social isolation, mistrust and powerlessness on the relationship between perceived neighborhood safety and psychological distress. Social isolation, mistrust and powerlessness were all found to have statistically significant mediating effects on 
the relationship between psychological distress and perception of neighborhood safety, supporting the second hypothesis and assertions made in previous literature (Ross \& Mirowsky, 2009). In the context of social stress theory, these findings suggest that mistrust, social isolation and powerlessness may be a reaction (secondary stressor) to feeling unsafe (primary stressor). The mediating relationship found further suggests that this reaction is a link between the environment and the internalization of stress.

Secondary stressors could provide an explanation to the ecological fallacy that asserts that it is false to assume that all people in a high-risk neighborhood will experience negative outcomes (Wheaton \& Clarke, 2003). Again, while conclusions about causation cannot be made, these findings do suggest that trust, social support and self-efficacy can offer protection to individuals experiencing the primary stressor of feeling unsafe in their neighborhood from experiencing psychological distress. For social work, understanding this mediating effect can be applied to creating interventions which increase social support, trust and power in neighborhoods where individuals report feeling unsafe, thus potentially impacting some mental health outcomes. In order to test the hypotheses about causal mechanisms, randomized control trials of interventions that target these areas are needed; however, for people who are living in environments that are unsafe and are not able to be altered, increasing feeling of support, power and trust may be one mechanism to improve overall levels of psychological distress.

It should also be noted that while it was found that powerlessness, social isolation and mistrust all mediate the relationship between feeling unsafe in one's neighborhood and psychological distress, there appears to be a difference between the potential impacts of each of these factors when examining the effect sizes of each model. The model that included powerlessness accounted for $32.09 \%$ total variation in psychological distress, a $20.41 \%$ increase over the model that includes the controls and feeling unsafe. This can be compared to the $1.13 \%$ and $.36 \%$ increase in overall variance accounted for when social isolation and trust are added respectively. While tests were not conducted to test if these differences in effect sizes were 
statistically significant, powerlessness appears to account for more of the variation in the psychological distress and therefore may have the largest overall impact if targeted in the creation of an intervention.

\section{Limitations $\mathcal{E}$ Future Research}

It should be noted that this study focuses on subjective neighborhood perceptions rather than geographical location or objective measures. Although it is unclear what impacts a person's perception of neighborhood safety, it is reasonable to hypothesize, based on previous research (Austin et al., 2002; Ellaway, Macintyre, \& Kearns, 2001; Sampson \& Raudenbush, 2004), that physical environment plays a substantial role. Previous studies have shown that not only are subjective measures of environment highly correlated with objective measures of neighborhood disorders, but also that subjective reality affects behavior and beliefs more directly. While this may limit the scope of the conclusions, we do not believe that it jeopardizes the overall significance of the findings.

In addition, this study was also limited by the sampling techniques that may have biased the sample. The use of landlines rather than cell phones selected out a potentially large portion of the population that could be both younger, due to their tendency to use cell phones, and of lower socioeconomic status, who may not be able to afford landlines. These issues with sampling might lead to results that are not accurately representative of Arizona's population as a whole and may not be fully capturing the experiences of ethnic minority groups and rural populations. Some of these limitations were addressed when weighting the sample but should still be considered when looking at the findings. Another limitation of the study was the use of single items to measure mistrust, perceptions of safety and powerlessness. Although the measures used have face validity, multiple items would help to insure the validity and reliability of these measures.

Although the findings of this study gives us insight into the relationship between perception of safety and psychological distress, it raises questions that still need to be explored. The main questions raised concern causation and the direction of the relationship found. Future research should assess 
what drives a person's perceptions of safety. Although it is reasonable to make the inference that a person's perception of safety is primarily influenced by the objective neighborhood environment in which they live, it is also possible that their perception is affected by the media, history of victimization and/or mental health diagnosis (i.e., schizophrenia). In addition, this research would be strengthened by the inclusion of both objective and subjective measures of neighborhood. Future research should match a person's subjective reports of feeling unsafe with objective measures of the neighborhood, such as crime rates or neighborhood socioeconomic status, to determine if concerns about safety cluster in neighborhoods that are characterized as "disordered." Future research should also explore what measures most effectively capture neighborhood disorder and have the biggest impact on those living in that neighborhood.

\section{Conclusions}

While a growing body of literature has established that social context matters in mental health outcomes, few studies have examined the specific mechanisms that impact those outcomes. This study adds to the existing body of literature that has examined the relationship between neighborhood factors on mental health by being the first, to our knowledge, to test the relationship between perceptions of neighborhood safety and psychological distress and explore possible protective factors. The significant mediating relationships found in this study suggest possible protective and risk factors that can be targeted in interventions, potentially improving mental health outcomes for individuals living in unsafe neighborhoods. Understanding specific neighborhood factors that impact mental health enabled us to design more effective interventions and is crucial to addressing mental health disparities.

\section{References}

Ahern, J., \& Galea, S. (2011). Collective efficacy and major depression in urban neighborhoods. American Journal of Epidemiology, 173, 1453-1462.

Aneshensel, C. S. (1992). Social stress: Theory and research. Annual Review of Sociology, 18, 15-38. 
Aneshensel, C. S., \& Sucoff, C. A. (1996). The neighborhood context of adolescent mental health. Journal of Health $\mathcal{E}$ Social Behavior, 37, 293-310.

Arizona Health Survey. (2008). Design and Methodology of the Arizona Health Survey. Phoenix, AZ: St. Luke's Health Initiatives.

Austin, D. M., Furr, L. A., \& Spine, M. (2002). The effects of neighborhood conditions on perceptions of safety. Journal of Criminal Justice, 30, 417-427.

Avison, W. R., \& Turner, R. J. (1988). Stressful life events and depressive symptoms: Disaggregating the effects of acute stressors and chronic strains. Journal of Health and Social Behavior, 29, 253-264.

Bandura, A. (2000). Exercise of human agency through collective efficacy. Current Directions in Psychological Science, 9, 75-78.

Beard, J. R., Cerda, M., Blaney, S., Ahern, J., Vlahov, D., \& Galea, S. (2009). Neighborhood characteristics and change in depressive symptoms among older residents of New York City. American Journal of Public Health, 99, 1308-1314.

Baron, R. M., \& Kenny, D. A. (1986). The moderator-mediator variable distinction in social psychological research: Conceptual, strategic, and statistical considerations. Journal of Personality and Social Psychology, 51, 1173-1182.

Bronfenbrenner, U. (1977). Toward an environmental ecology of human development. American Psychologist, 32, 513-531.

Brown, S. C., Mason, C. A., Lombard, J. L., Martinez, F., Plater-Zyberk, E., Spokane, A. R., Newman F. L., Pantin, H., \& Szapocznik, J. (2009). The relationship of built environment to perceived social support and psychological distress in Hispanic elders: The role of "Eyes on the street". The Journals of Gerontology Series B: Psychological Sciences and Social Sciences, 64, 234-246.

Brundtland, G. H. (2000). Mental health in the 21st century. Bulletin of the World Health Organization, 78, 411.

Christie-Mizell, C., Steelman, L. C., \& Stewart, J. (2003). Seeing their surroundings: The effects of neighborhood setting and race on maternal distress. Social Science Research, 32, 402-428.

Downey, L., \& Van Willigen, M. (2005). Environmental stressors: The mental health impacts of living near industrial activity. Journal of Health and Social Behavior, 46, 289-305.

Ellaway, A., Macintyre, S., \& Kearns, A. (2001). Perceptions of place and health in socially contrasting neighborhoods. Urban Studies, 38, 2299-2316.

Elliott, M. (2000). The stress process in neighborhood context. Health E Place, 6, 287-299.

Faris, R. E. L., \& Dunham, H. W. (1939). Mental disorders in urban areas: An ecological study of schizophrenia and other psychoses. Oxford, England: University of Chicago Press.

Fitzpatrick, K. M., \& LaGory, M. (2003). "Placing" health in an urban sociology: Cities as mosaics of risk and protection. City $\mathcal{E}$ Community, 2, 33-46. 
Galea, S., Ahern, J., Nandi, A., Tracy, M., Beard, J., \& Vlahov, D. (2007). Urban neighborhood poverty and the incidence of depression in a population-based cohort study. Annals of Epidemiology, 17, 171179.

Galea, S., Ahern, J., Rudenstine, S., Wallace, Z., \& Vlahov, D. (2005). Urban built environment and depression: A multilevel analysis. Journal of Epidemiology and Community Health, 59, 822-287.

Geis, K. J., \& Ross, C. E. (1998). A new look at urban alienation: The effect of neighborhood disorder on perceived powerlessness. Social Psychology Quarterly, 61, 232-246.

Hiroto, D. S. (1974). Locus of control and learned helplessness. Journal of Experimental Psychology, 102, 187-193.

House, J. S., Strecher, V., Metzner, H. M., \& Robbins, C. (1986). Occupational stress and health among men and women in the Tecumseh Community Health Study. Journal of Health and Social Behavior, 27, 62-77.

Kessler, R. C., \& McLeod, J. D. (1985). Social support and mental health in community samples. In S. Cohen \& S. L. Syme (Eds.), Social support and health (pp. 219-240). New York: Academic Press.

Kessler, R. C., Berglund, P. A., Foster, C. L., Saunders, W. B., Stang, P. E., \& Walters, E. E. (1997). Social consequences of psychiatric disorders, II: Teenage parenthood. American Journal of Psychiatry, 154, 1405-1411.

Kessler, R. C., Walters, E. E., \& Forthofer, M. S. (1998). The social consequences of psychiatric disorders, III: Probability of marital stability. American Journal of Psychiatry, 155, 1092-1096.

Kessler, R. C., Andrews, G., Colpe, L. J., Hiripi, E., Mroczek, D. K., Normand, S. L. T., Walters, E. E., \& Zaslavsky, A. M. (2002). Short screening scales to monitor population prevalence and trends in non-specific psychological distress. Psychological Medicine, 32, 959-976.

Leventhal, T., \& Brooks-Gunn, J. (2003). Moving to opportunity: An experimental study of neighborhood effects on mental health. American Journal of Public Health, 93(9), 1576-1582.

Liska, A. E. (1997). Modeling the relationships between macro forms of social control. Annual Review of Sociology, 23, 39-61.

Mair, C., Roux, A., \& Galea, S. (2008). Are neighbourhood characteristics associated with depressive symptoms? A review of evidence. Journal of Epidemiology and Community Health, 62, 940-946.

Maslow, A. H. (1987). Motivation and personality (3rd ed.). New York: Harper Collins.

Macintyre, S., \& Ellaway, A. (2003). Neighborhood and health: An overview. In I. Kawachi \& L. F. Berkman (Eds.), Neighborhood and health (pp. 20-42). New York: Oxford University Press.

Mickelson, K. D., \& Kessler, R. C. (1997). Adult attachment in nationally representative sample. Journal of Personality and Social Psychology, 73, 1092-1106. 
Patel, V., Flisher, A. J., \& Cohen, A. (2006). Mental health. In M. H. Merson, R. E. Black, A. J. Mills (Eds.), International public health: Diseases, programs, aystems and policies (pp. 355-392). Sudbury, MA: Jones and Bartlett Publishers.

Pearlin, L. I. (1989). The sociological study of stress. Journal of Health and Social Behavior, 30, 241-256.

Phongsavan, P., Chey, T., Bauman, A., Brooks, R., \& Silove, D. (2006). Social capital, socio-economic status and psychological distress among Australian adults. Social Science \& Medicine, 63, 2546-2561.

Prince, M., Patel, V., Saxena, S., Maj, M., Maselko, J., Phillips, M. R., \& Rahman, A. (2007). No health without mental health. The Lancet, 370, 859-877.

Propper, C., Jones, K., Bolster, A., Burgess, S., Johnston, R., \& Sarker, R. (2005). Local neighborhood and mental health: Evidence from the UK. Social Science \& Medicine, 61, 2065-2083.

Regier, D. A., Farmer, M. E., Rae, D. S., Locke, B. Z., Keith, S. J., Judd, L. L., \& Goodwin, F. K. (1990). Comorbidity of mental disorders with alcohol and other drug abuse: Results from the epidemiologic catchment area (ECA) study. Journal of the American Medical Association, 264, 2511-2518.

Roh, S., Jang, Y., Chiriboga, D. A., Kwag, K. H., Cho, S., \& Bernstein, K. (2011). Perceived neighborhood environment affecting physical and mental health: A study with Korean American older adults in New York City. Journal of Immigrant and Minority Health, 1-8. doi: DOI: 10.1007/s10903-011-9492-3

Ross, C. E., \& Jang, S. S. (2000). Neighborhood disorder, fear, and mistrust: The buffering role of social ties with neighbors. American Journal of Community Psychology, 28, 401-420.

Ross, C. E., \& Huber, J. (1985). Hardship and depression. Journal of Health and Social Behavior, 26, 312-327.

Ross, C. E., \& Mirowsky, J. (2009). Neighborhood disorder, subjective alienation and distress. Journal of Health and Social Behavior, 50, 49-64.

Ross, C. E., Mirowsky, J., \& Pribesh, S. (2001). Powerlessness and the amplification of threat: Neighborhood disadvantage, disorder, and mistrust. American Sociological Review, 66, 568-591.

Saleebey, D., (2004). "The Power of Place": Another look at the environment. Families in Society, 85, 7-16.

Sampson, R. J., \& Raudenbush, S. W. (2004). Seeing disorder: Neighborhood stigma and the social construction of "broken windows." Social Psychology Quarterly, 67, 319-342.

Sampson, R. J., Raudenbush, S. W., \& Earls, F. (1997). Neighborhoods and violent crime: A multilevel study of collective efficacy. Science, 277, 918-924.

Silver, E., Mulvey, E. P., \& Swanson, J. W. (2002). Neighborhood structural characteristics and mental disorder: Faris and Dunham revisited. Social Science \& Medicine, 55, 1457-1470. 
Sobel, M. E. (1982). Asymptotic confidence intervals for indirect effects in structural equation models. In S. Leinhart (Ed.), Sociological methodology 1982 (pp. 290-312). San Francisco: JosseyBass.

Stockdale, S. E., Wells, K. B., Tang, L., Belin, T. R., Zhang, L., \& Sherbourne, C. D. (2007). The importance of social context: Neighborhood stressors, stress-buffering mechanisms, and alcohol, drug, and mental health disorders. Social Science $\mathcal{E}$ Medicine, 65, 1867-1881.

Taylor, S. E., Repetti, R. L., \& Seeman, T. (1997). Health psychology: What is an unhealthy environment and how does it get under the skin? Annual Review of Psychology, 48, 411. (need pages)

Thoits, P. A. (1983). Multiple identities and psychological well-being: A reformulation and test of the social isolation hypothesis. American Sociological Review, 48, 174-187.

Truong, K. D., \& Ma, S. (2006). A systematic review of relations between neighborhoods and mental health. The Journal of Mental Health Policy and Economics, 9, 137-154.

Wakefield, J. C. (1999). Measuring mental illness. In A.V Horwitz \& T. L Scheid (Eds.), Handbook for the study of mental health: Social context, theories and systems (pp. 29-58). Cambridge: Cambridge University Press.

Wells, J. E., Bushnell J.A., Hornblow, R., Joyce, P. R., \& Oakley-Browne, M. A. (1989). Christchurch psychiatric epidemiology study, part 1: Methodology and lifetime prevalence for specific psychiatric disorders. Australian-New Zealand Journal of Psychiatry, 23, 315326.

Wen, M., Hawkley, L. C., \& Cacioppo, J. T. (2006). Objective and perceived neighborhood environment, individual SES and psychosocial factors, and self-rated health: An analysis of older adults in Cook County, Illinois. Social Science $\mathcal{E}$ Medicine, 63, 2575-2590.

Wheaton, B., \& Clarke, P. (2003). Space meets time: Integrating temporal and contextual influences on mental health in early adulthood. American Sociological Review, 68, 680-706.

Williams, D. R., Neighbors, H. W., \& Jackson, J. S. (2008). Racial/ ethnic discrimination and health: Findings from community studies. American Journal of Public Health, 98, S29-S37. 